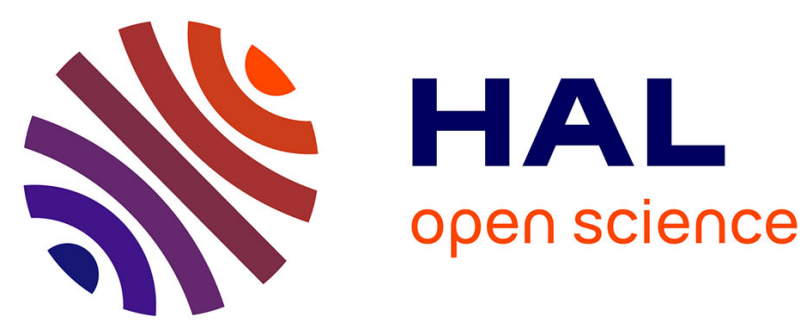

\title{
Estimation of heat flux parameters during static gas tungsten arc welding spot under argon shielding
}

Sreedhar Unnikrishnakurup, Sébastien Rouquette, Fabien Soulié, Gilles Fras

\section{To cite this version:}

Sreedhar Unnikrishnakurup, Sébastien Rouquette, Fabien Soulié, Gilles Fras. Estimation of heat flux parameters during static gas tungsten arc welding spot under argon shielding. International Journal of Thermal Sciences, 2017, 114, pp.205-212. 10.1016/j.ijthermalsci.2016.12.008 . hal-01576966

\section{HAL Id: hal-01576966 https://hal.science/hal-01576966}

Submitted on 24 Aug 2017

HAL is a multi-disciplinary open access archive for the deposit and dissemination of scientific research documents, whether they are published or not. The documents may come from teaching and research institutions in France or abroad, or from public or private research centers.
L'archive ouverte pluridisciplinaire HAL, est destinée au dépôt et à la diffusion de documents scientifiques de niveau recherche, publiés ou non, émanant des établissements d'enseignement et de recherche français ou étrangers, des laboratoires publics ou privés. 


\title{
Estimation of heat flux parameters during static gas tungsten arc welding spot under argon shielding
}

\author{
Sreedhar Unnikrishnakurup*, Sébastien Rouquette, Fabien Soulié, Gilles Fras \\ Laboratoire de Mécanique et Génie Civil (LMGC), Université de Montpellier, CNRS, Montpellier, France
}

\begin{abstract}
A multi-physics modelling of a static Gas Tungsten Arc Welding (GTAW) operation has been established in order to estimate the heat flux exchanged between the arc plasma and the work-piece. The heat flux was described with a Gaussian function where two parameters required to be estimated: process effi-ciency and radial distribution. An inverse heat transfer problem (ihtp) has been developed in the aim to estimate these parameters from experimental data. Levenberg-Marquardt algorithm was used as the regularization method in addition to an iterative process. The experiment consisted in a static spot weld with GTAW process. The weld spot was on for $5 \mathrm{~s}$ under Argon shielding gas, $2.4 \mathrm{~mm}$ pure tungsten electrode on a SS304L disc. Temperatures were measured with thermocouples and weld pool growth monitored with a high speed camera. The experimental data were used to solve the ihtp what led to values such as 0.7 for process efficiency and average radial distribution of $1.8 \mathrm{~mm}$.
\end{abstract}

Keywords:

Gas tungsten arc welding, Numerical simulation of welding, Heat flux estimation, Inverse heat transfer problem

\section{Introduction}

Gas Tungsten Arc Welding (GTAW) is an assembly process by a localised fusion of two materials with the required energy provided from an electric arc plasma. This welding process produces excellent joint quality especially for critical assemblies such as the one required in aerospace, nuclear, petro-chemical industries. In the three last decades, tremendous amount of work have been published in the aim to understand the basic phenomena occurring in arc welding processes $[1,2,3,4,5,6]$. The use of finite element software are still useful for predicting temperature field and molten flow in the fusion zone. Recently, several welding simulations were performed by considering all the physics involved in the weld pool $[6,7]$. All these models require the specification of net thermal input from the arc plasma to the work piece surface. Rosenthal [8] proposed a mathematical model of the moving heat source under the assumptions of quasi-stationary state and concentrated point heating in the 3D analysis. Pavelic et al. [9] suggested a circular disc heat source model with Gaussian distribution of heat flux on the surface of work piece. Goldak et al. [10] further developed a double ellipsoidal power density distribution of heat source model below

\footnotetext{
* Corresponding author. 8.7 Division/Section Thermografische Verfahren, Unter den Eichen 87, 12205 Berlin, Germany.

E-mail address: sreedhar.aie@gmail.com (S. Unnikrishnakurup).
}

the welding arc to simulate correctly any kind of welding processes. These heat source models have been also used in welding simulation for predicting sample distortions and residual stresses [11]. In this work, a static Gas Tungsten Arc Welding (GTAW) operation has been investigated both experimentally and numerically. It is well known that the heat flux absorbed by the work-piece from the arc plasma relies strongly upon the different welding conditions (welding intensity, shielding gas mixture, electrode size and composition). The heat flux distribution influences the temperature distribution on and in the molten weld pool and consequently the surface tension of molten metal. Modification of surface tension on weld pool surface results as changes of the molten metal flow in the weld pool. So it is a matter of interest to know correctly the heat flux absorbed by the work-piece in order to predict accurately the flow in the molten pool and the final shape of the fused zone. The heat flux was modelled with a Gaussian function involving two experimental parameters which were process efficiency and radial distribution. Then an inverse problem has been stated in order to estimate these heat flux parameters from experimental data. Such inverse problems have been intensively used in the welding literature for the assessment of heat flux, material properties, liquid/ solid interface for instance $[12,13,14,15]$. The resolution of the inverse problem requires a regularization method as well as experimental data such as thermal histories, weld pool evolution. An iterative procedure coupled to the Levenberg-Marquardt technique [16] has been used to solve the stated inverse problem. It was 
considered that some variables involved in the GTAW numerical simulation such as welding current, voltage, material properties, surface tension of molten metal are known with a reasonable accuracy. The inverse heat transfer problem (ihtp) was firstly investigated numerically in order to validate the robustness of solution by introducing errors in the input data. Afterwards, the ihtp was solved with data measured during a GTAW spot weld operation with a duration of $5 \mathrm{~s}$ on a SS304L cylindrical disc sample.

\section{Mathematical modeling and simulation}

\subsection{Assumptions and governing equations}

The computational model for the current study is limited to the workpiece, with a specific focus on the weld pool. The multiphysics problem comprises electromagnetism, fluid flow and heat transfer [17]. Fig. 1 shows the different transport phenomena occurring in the welding process. The molten weld pool and the different forces considered for the current study are also represented in Fig. 1.

The major assumptions made for the simplification of the problem are:

1 Static TIG welding (the arc is stationary) is carried out and the 2D-axisymmetric model is assumed. The radial position is defined by $r$.

2 Molten metal flows in the weld pool are considered as laminar and incompressible due to the small size of the weld pool.

3 Buoyancy force is taken into account using the Boussinesq approximation [7] as well as the latent heat of fusion.

4 The surface tension coefficient is both temperature and sulfur content dependent using the Sahoo et al. relationship [18].

$\frac{\partial \gamma}{\partial T}=-A_{\gamma}-R_{g} \Gamma_{s} \ln \left(1+K a_{s}\right)-\frac{K a_{s}}{1+K a_{s}} \frac{\Gamma_{s} \Delta H_{0}}{T}$

$K(T)=k_{1} \exp \left(-\frac{\Delta H_{0}}{R_{g} T}\right)$

where parameters $A_{\gamma}, R_{g}, \Gamma_{s}, a_{s}, \Delta H_{0}$ and $k_{1}$ are defined and given in Table 1.

5 A flat weld pool surface is considered. The assumption of a flat pool surface is reasonable because the deformation of the pool surface is low for welding currents below $200 \mathrm{~A}$ [19].

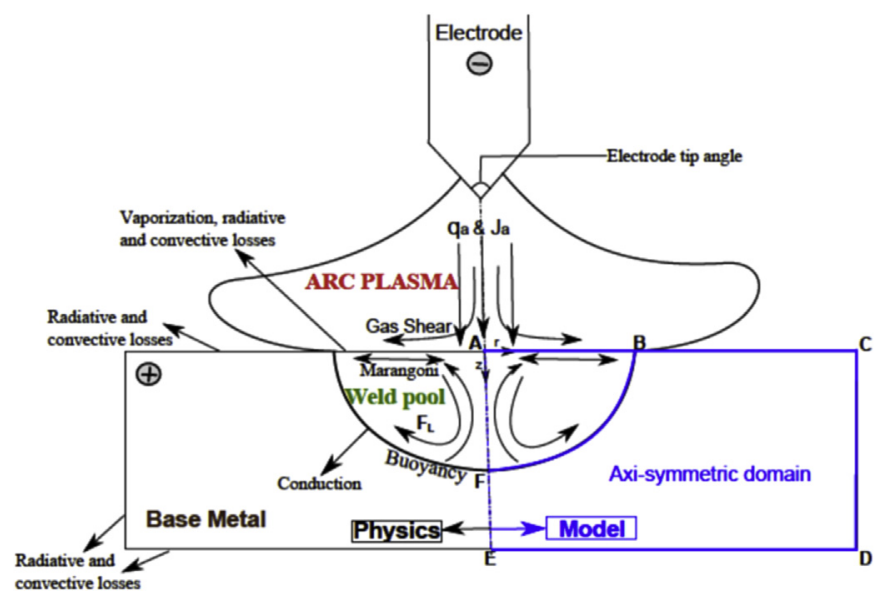

Fig. 1. Schematic of transport phenomena occurring in the GTA Welding process.
Table 1

Material properties of Stainless Steel 304L [20] and welding conditions used in the GTA spot welding simulation. Values for solid state (s) are in the temperature range $293 \mathrm{~K}$ - solidus. Values for liquid state (l) are in the range liquidus - $3000 \mathrm{~K}$. Linear dependance with temperature is assumed for the values of the thermophysical properties.

\begin{tabular}{|c|c|c|}
\hline Symbol & Nomenclature & Value \\
\hline$a_{s}$ & Activity of sulfur & 0.0039 wt $\%$ \\
\hline$A_{\gamma}$ & Constant in surface tension gradient & $4.3 \times 10^{-4} \mathrm{~N} \mathrm{~m}^{-1} \mathrm{~K}^{-1}$ \\
\hline$R_{g}$ & Gas constant & $8314.3 \mathrm{~J} \mathrm{~kg}^{-1} \mathrm{~mol}^{-1} \mathrm{~K}^{-1}$ \\
\hline$\Delta H_{0}$ & Standard heat of adsorption & $-1.88 \times 10^{8} \mathrm{~J} \mathrm{~kg}^{-1} \mathrm{~mol}^{-1}$ \\
\hline$\Gamma_{s}$ & Surface excess at saturation & $1.3 \times 10^{-8} \mathrm{~J} \mathrm{~kg}^{-1} \mathrm{~mol}^{-1} \mathrm{~m}^{-2}$ \\
\hline$k_{1}$ & Entropy factor & $3.18 \times 10^{-3}$ \\
\hline$\gamma_{m}$ & Surface tension at pure metal & $1.943 \mathrm{~N} \mathrm{~m}^{-1}$ \\
\hline$\beta$ & Thermal expansion coefficient & $1 \times 10^{-4} \mathrm{~K}^{-1}$ \\
\hline$\sigma_{e}$ & Electrical conductivity & $7.7 \times 10^{5} \Omega^{-1} \mathrm{~m}^{-1}$ \\
\hline$L_{f}$ & Latent heat of fusion & $2.47 \times 10^{5} \mathrm{~J} \mathrm{~kg}^{-1}$ \\
\hline$T_{S}$ & Solidus temperature & $1673 \mathrm{~K}$ \\
\hline$T_{l}$ & Liquidus temperature & $1723 \mathrm{~K}$ \\
\hline$T_{0}$ & Ambient temperature & $293 \mathrm{~K}$ \\
\hline$\rho_{0}$ & Reference density & $7200 \mathrm{~kg} \mathrm{~m}^{-3}$ \\
\hline$\rho(T)$ & Density & $\begin{array}{l}\mathrm{s}: 7900-7200 \mathrm{~kg} \mathrm{~m}^{-3} \\
\mathrm{l}: 6900-5800 \mathrm{~kg} \mathrm{~m}^{-3}\end{array}$ \\
\hline$c_{p}(T)$ & Specific heat & $\begin{array}{l}\mathrm{s}: 480-725 \mathrm{~J} \mathrm{~kg} \mathrm{~K}^{-1} \\
\mathrm{l}: 800 \mathrm{~J} \mathrm{~kg} \mathrm{~K}^{-1}\end{array}$ \\
\hline$k(T)$ & Thermal conductivity & $\begin{array}{l}\mathrm{s}: 12-32.5 \mathrm{~W} \mathrm{~m}^{-1} \mathrm{~K}^{-1} \\
\mathrm{l}: 17.5-22 \mathrm{~W} \mathrm{~m}^{-1} \mathrm{~K}^{-1}\end{array}$ \\
\hline$\mu(T)$ & Viscosity & $\begin{array}{l}\mathrm{s}: 1 \times 10^{5} \mathrm{~kg} \mathrm{~m}^{-1} \mathrm{~s}^{-2} \\
\mathrm{l}: 0.0067 \mathrm{~kg} \mathrm{~m}^{-1} \mathrm{~s}^{-2}\end{array}$ \\
\hline h & Convective heat transfer coefficient & $15 \mathrm{~W} \mathrm{~m}^{-2} \mathrm{~K}^{-1}$ \\
\hline$\varepsilon$ & Emissivity coefficient & 0.8 \\
\hline I & Current & $70 \mathrm{~A}$ \\
\hline $\mathrm{U}$ & Voltage & $9.4 \mathrm{~V}$ \\
\hline$\eta$ & Efficiency & 0.68 \\
\hline$R_{B}$ & Gaussian heat distribution radius & $1.6 \times 10^{-3} \mathrm{~m}$ \\
\hline$C T W D$ & Contact tip to work distance & $2.4 \times 10^{-3} \mathrm{~m}$ \\
\hline
\end{tabular}

6 The spatially distributed heat flux, current and arc drag force falling on the free surface have Gaussian expressions.

The fluid flow in the weld pool is driven by a combination of electromagnetic, buoyancy, surface tension, arc drag and arc pressure forces. The forces involved in the weld pool are depicted in Fig. 1. They can be classified into two categories: the volumetric forces and surface forces. The gravitational force and electromagnetic force which are acting inside the weld pool are considered as volumetric forces. The thermocapillary shear stress (surface tension force) and arc drag force are acting on the boundary of the weld pool and are considered as surface forces. From the previous studies, for low welding currents (less than $200 \mathrm{~A}$ ), the arc pressure acting normally to the weld pool is negligible and is not taken into account in the present study and that leads to a flat weld pool surface.

The electromagnetic force can be calculated first, independently of the other governing equations as the welding intensity is quasiconstant along the welding operation. Furthermore a steady state analysis is carried out for the electric potential problem as the welding intensity is reached almost instantaneously after striking the electric arc. The computation of Lorentz force requires both terms: current density vector $\mathbf{j}$ and the self-induced azimuthal magnetic field $B_{\theta}$. These two terms can be deduced from the solution of electrical potential $\phi(r, z)$ equation, which is given as follows:

$\nabla^{2} \phi=\frac{1}{r} \frac{\partial}{\partial r}\left(r \sigma_{e} \frac{\partial \phi}{\partial r}\right)+\frac{\partial}{\partial z}\left(\sigma_{e} \frac{\partial \phi}{\partial z}\right)=0$

and the current density is calculated according to Ohms Law 
$j_{r}=-\sigma_{e} \frac{\partial \phi}{\partial r} \quad j_{z}=-\sigma_{e} \frac{\partial \phi}{\partial z}$

the self-induced azimuthal magnetic field is derived from Ampère's law

$B_{\theta}=\frac{\mu_{0}}{r} \int_{0}^{r} j_{z} r \partial r$

where $\sigma_{e}$ is electrical conductivity, $\phi$ electrical potential, $j_{r}$ and $j_{z}$ are radial and axial current density respectively and $\mu_{0}=4 \pi \times 10^{-7} \mathrm{H} /$ $\mathrm{m}$ the permeability of vacuum.

The fluid flow and temperature are governed by the following classical equations.

Conservation of mass

$\frac{\partial \rho}{\partial t}+\nabla \cdot(\rho \mathbf{u})=0$

Conservation of momentum

$$
\begin{aligned}
\rho\left(\frac{\partial \mathbf{u}}{\partial t}+\mathbf{u} \cdot \nabla \mathbf{u}\right)= & -\nabla p+\mu \nabla \cdot\left(\nabla \mathbf{u}+{ }^{t} \nabla \mathbf{u}\right)+\mathbf{j} \times \mathbf{B}+\rho_{0}(1 \\
& \left.-\beta\left(T-T_{r e f}\right)\right) \mathbf{g}
\end{aligned}
$$

where $\mathbf{u}$ is the velocity vector field, $t$ is time, $\rho_{0}$ is a reference density, $\mu$ is viscosity, $p$ is pressure field, $g$ is gravity and $T_{r e f}$ is a reference temperature fixed to the solidus temperature of the base material.

Conservation of energy

$\rho c_{p}^{e q}\left(\frac{\partial T}{\partial t}+\mathbf{u} \cdot \nabla T\right)=\nabla \cdot(k \nabla T)+\mathbf{J} \cdot \mathbf{E}$

where $T$ is temperature, $c_{p}^{e q}=c_{p}+L_{f} \frac{d f_{L}}{d T}$ is an equivalent specific heat introduced to take into account the latent heat of fusion $L_{f} . f_{L}$ is the liquid fraction, assumed to vary linearly with temperature in the mushy zone [21].

\subsection{Studied domain and associated boundary conditions}

The domain is limited to the work-piece in order to simplify the modelling (hence no plasma modelling is required) and to get reasonable computation times. As the welding torch is fixed and the work-piece is a metallic disc (made of SS304L with size of $4 \mathrm{~mm}$ thickness and $80 \mathrm{~mm}$ diameter), the studied problem is 2D axisymmetric and the geometric domain can be represented as a rectangle, see Fig. 2, where the boundary AE is symmetry axis.

The geometry (ABCDEF) includes two sub-domains $\Omega_{1}$ (BCDEF) and $\Omega_{2}(\mathrm{ABF})$. The three governing equations (electric, energy and fluid) are only applied to sub-domain $\Omega_{2}$ while energy and electric conservations are only solved for sub-domain $\Omega_{1}$. The size of subdomain $\Omega_{2}$, where the weld pool forms and grows, is evaluated

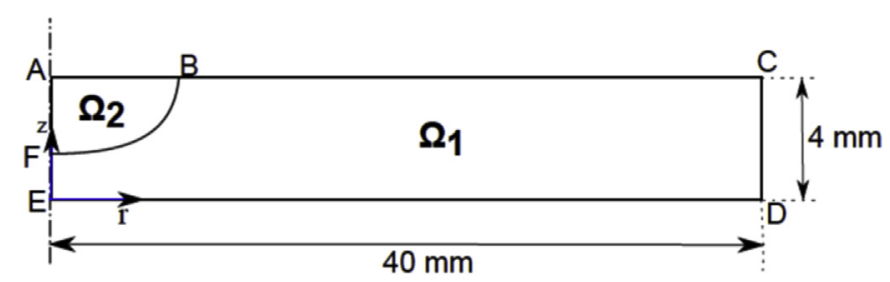

Fig. 2. Studied domain for the finite element (FE) analysis. from experimental macrographies. Such strategy allows saving computation time. The two sub-domains are discretized with triangular elements. A finer meshgrid is adopted for the fluid domain $\Omega_{2}, 120 \mu \mathrm{m}$, with $60 \mu \mathrm{m}$ on both top surface (AB) and symmetry axis (AF) where high gradients (temperature, surface tension and velocity) occur [7]. The meshgrid of sub-domain $\Omega_{1}$ was set to $1 / 3$ of millimeter. Such meshgrid resulted in 16122 degree of freedom (dof). A second order polynomial interpolation was used for both temperature and velocity while a first order is used for the pressure. The meshgrid of the sub-domains remains the same during the simulation.

The different boundary conditions for temperature $T$, electric potential $\phi$ and velocity vector $\mathbf{u}$ are given in Table 2 . The pressure boundary conditions are free excepted for one point at the liquidsolid interface where pressure is set to zero in order to facilitate the convergence of numerical calculations.

Concerning the thermal boundary conditions, the heat flux $q_{a}(r)$ acting on top surface of the work piece and mathematically defined with a Gaussian function:

$q_{a}(r)=\eta \frac{U I}{2 \pi R_{B}^{2}} e^{-\left(\frac{r}{R_{B}}\right)^{2}}$

The Gaussian heat input was defined by the arc power ( $U$ and $I$ ) and the Gaussian heat distribution parameter $R_{B}$. The efficiency $\eta$ introduces the ability of energy transfer from cathode to anode, including vaporization, radiative and convective losses in the arc (Fig. 1). Additionally, convection $\left(q_{c}\right)$ and radiation $\left(q_{r}\right)$ are applied on the free surface:

$q_{c}=h\left(T-T_{0}\right) \quad q_{r}=\sigma \varepsilon\left(T^{4}-T_{0}^{4}\right)$

where $\sigma$ is Stefan-Boltzmann constant $\left(5.67 \times 10^{-8} \mathrm{~W} \mathrm{~m}^{-2} \mathrm{~K}^{-4}\right)$.

The current density $J_{a}(r)$ on the top surface is classically defined as a Gaussian function:

$J_{a}(r)=\frac{1}{2} \frac{I}{\pi R_{J}^{2}} e^{-\frac{1}{2}\left(\frac{r}{R_{J}}\right)^{2}}$

The Gaussian current density distribution parameter $R_{J}$ is calculated according an empirical equation from Ref. [22]; $R_{J}=0.5342 I^{0.2684}$, where $R_{J}$ is in millimeter and $I$ is in ampere.

Concerning the boundary condition on velocity, the velocity vector is equal to zero on all the limits of domain $\left(\Omega_{2}\right)$, except on $(\mathrm{AF})$ where $\frac{\partial u_{z}}{\partial r}=0$ and on $(\mathrm{AB})$ where a flat top surface is assumed for the weld pool $\left(u_{z}=0\right)$ and where:

$\mu \frac{\partial u_{r}}{\partial r}=\tau_{s t}=f_{L} \frac{\partial \gamma}{\partial T} \frac{\partial T}{\partial r}+\tau_{a}$

The thermocapillary factor $\frac{\partial \gamma}{\partial T}$ is given by equation (1) [18]. The

Table 2

Boundary conditions applied for the GTA welding simulation. The boundaries are defined according to Fig. 2.

\begin{tabular}{llll}
\hline Boundary & $T$, eq. (8) and (9) & $\phi$, eq. (10) & u, eq. (11) \\
\hline $\mathrm{AB}$ & $\frac{\partial T}{\partial r}=q_{a}(r)-q_{c}-q_{r}$ & $J_{a}(r)$ & $\mu \frac{\partial u_{r}}{\partial r}=\tau_{s t}, u_{z}=0$ \\
$\mathrm{BC}$ & $\frac{\partial T}{\partial r}=q_{a}(r)-q_{c}-q_{r}$ & $J_{a}(r)$ & $\mathbf{0}$ \\
$\mathrm{DE}$ & $\frac{\partial T}{\partial z}=-q_{c}-q_{r}$ & $\frac{\partial \phi}{\partial z}=0$ & $\mathbf{0}$ \\
$\mathrm{CD}$ & $\frac{\partial T}{\partial z}=-q_{c}-q_{r}$ & $\frac{\partial \phi}{\partial z}=0$ & $\mathbf{0}$ \\
$\mathrm{AF}$ & $\frac{\partial T}{\partial r}=0$ & $\frac{\partial \phi}{\partial r}=0$ & $u_{r}=0, \frac{\partial u_{z}}{\partial r}=0$ \\
$\mathrm{EF}$ & $\frac{\partial T}{\partial r}=0$ & $\frac{\partial \phi}{\partial r}=0$ & $\mathbf{0}$ \\
\hline
\end{tabular}


arc drag force $\tau_{a}$ is classically described by a Gaussian function $[5,6]$

$\tau_{a}=P_{M} \sqrt{\frac{r}{R_{S}}} \exp \left(-\left(\frac{r}{R_{S}}\right)^{2}\right)$

where $P_{M}=46 \mathrm{~Pa}$ and $R_{S}=3 \mathrm{~mm}$. These values are chosen from literature with the similar experimental conditions.

The welding intensity $I$ and voltage $U$ are measured during each spot welding tests in order to use them in the simulation (Fig. 3). The welding conditions used for the FE analysis are summarized in Table 1.

The thermophysical properties of Stainless Steel 304L used hereafter in this work are temperature dependent and their behaviour is linear with the temperature (Table 1 ).

\subsection{Simulation vs experimental results}

Simulations and experiments of spot welding were realized in similar conditions (Table 1) on SS304L disks samples.

The chemical composition of SS304L samples, and specially sulfur content that directly influences Marangoni thermoconvection (see eq. (1)), was controlled by electron probe microanalysis (EPMA). During experiments, process parameters voltage $U$ and current $I$ were recorded at $10 \mathrm{kHz}$ (see Fig. 3). The average value of current is constant during the whole welding operation. A small peak in voltage can be observed at $0.5 \mathrm{~s}$ because of the arc initiation with lift arc method. This variation is limited to $10 \%$ increase of the average value and completely disappears after $1.5 \mathrm{~s}$. The temperatures were recorded with type $\mathrm{K}$ thermocouples, size $0.5 \mathrm{~mm}$, embedded in small drilled holes of $0.5 \mathrm{~mm}$ depth on the back side of the sample in order to avoid direct arc radiation. Thermocouples locations in regard of the center of the weld pool were post-mortem controlled by macrography and micrography analysis.

Comsol Multiphysics ${ }^{\odot}$ was used to perform the Finite Element (FE) analysis of the stated GTAW modelling. This FE software has demonstrated its ability to solve such multi-physics welding problems [16,15]. The FE analysis is organised in two steps with Comsol and Matlab ${ }^{\circledR}$ : first the electric potential field is computed in order to get the Lorentz force as it affects the molten metal flow in the weld pool. Secondly the coupled Navier-Stokes and energy equations are solved. Such strategy allows saving cpu memory. Maximum step time was fixed to $0.05 \mathrm{~s}$ in Comsol software and the adaptative step time was set to on in order to improve the convergence by decreasing the time step. The solid/liquid interface

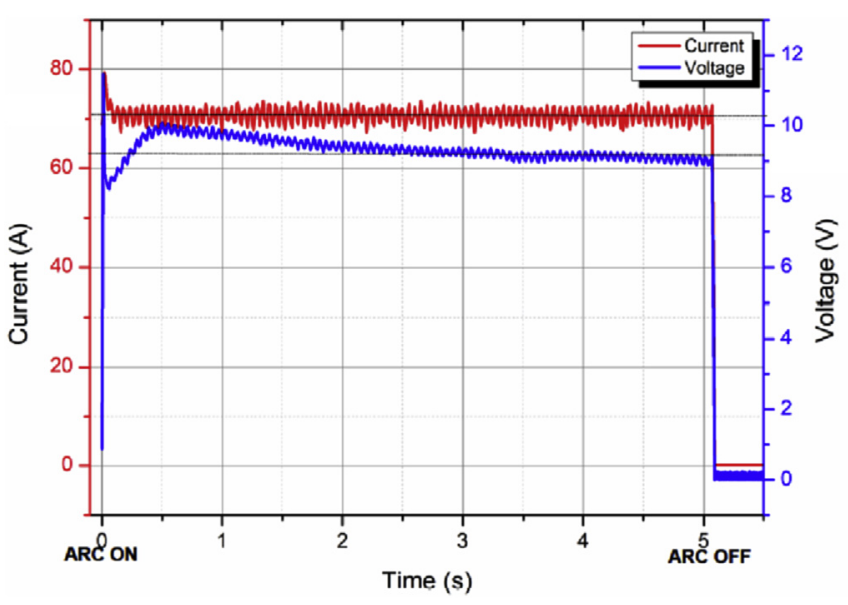

Fig. 3. Process parameters (current and voltage) during spot welding. is post-processed by tracking the solidus isotherm $1673 \mathrm{~K}$. The CPU time was about $534 \mathrm{~s}$ on laptop with windows 7 OS 64 bits with 2 microprocessor Intel Core i5-2540M running at $2.6 \mathrm{GHz}$ and $4 \mathrm{~GB}$ memory. The numerical results are presented in Figs. 4 and 5 and they are compared to experimental ones under the same welding conditions.

Fig. 4 shows the macrography of the welded SS304L sample (weld pool half-width is $2 \mathrm{~mm}$ and penetration is $1.4 \mathrm{~mm}$ ) on the left side. On the right is presented the temperature distribution at the end of the simulation ( $t=5.15 \mathrm{~s}$ ). The isotherm $1673 \mathrm{~K}$ is used to identify the liquid/solid interface. From the numerical result, the predicted size of the weld pool is about $2 \mathrm{~mm}$ for the half-width and $1.3 \mathrm{~mm}$ for the penetration. It can be noticed that the experimental weld pool surface is slightly convex contrary to our flat surface assumption. The simulated and experimental weld pool shapes are similar. The simulated results show that the fluid flow is inward (from the edge of the weld pool towards its centre) and the maximum molten metal velocities, about $45.6 \mathrm{~cm} / \mathrm{s}$, are reached along the symmetry axis.

This flow behaviour is mainly due to the Marangoni force (surface tension effect) as the three other forces acting on the weld pool, Lorentz, Boussinesq and arc drag, are low for such welding intensities [5,6].

Temperature evolutions, simulated $T_{\text {sim }}$ and measured $T_{\text {exp }}$, at two locations on the sample backside are shown in Fig. 5. The main discrepancy is on the temperature dynamic between $T_{\text {ini }}$ and $T_{\text {final }}$. At $t_{\text {final }}$, the simulated and measured are almost $\operatorname{similar}(\Delta T<40 \mathrm{~K})$ while the simulated was higher during the time interval $[0-5 s]$ ( $\Delta T$ was about $130 \mathrm{~K}$ at $t=2 \mathrm{~s}$ ). The two simulated temperatures exhibit the same behaviour. That probably means the heat input is too important at the beginning and varies along the weld spot duration. The weld spot was applied on top side of the sample for $r=0 \mathrm{~mm}$ what explains that simulated temperature recorded at $r=0.5 \mathrm{~mm}$ reaches higher values than the one at $r=3.4 \mathrm{~mm}$ $(\Delta T \sim 260 \mathrm{~K})$. The temperature difference measured experimentally is lower between the two sensors $\sim 210 \mathrm{~K}$.

The weld pool growth is presented in Fig. 6 through the weld pool (WP) half-width and depth evolutions. Predicted WP halfwidth shows a faster growth within $1.5 \mathrm{~s}$ of simulation then its evolution is almost linear till the final time. Final WP half-width is about $1.9 \mathrm{~mm}$ while its depth is around $1.3 \mathrm{~mm}$. The WP depth evolution exhibits some oscillations probably due to some numerical instabilities caused by the size of finite element that are probably too coarse (60 $\mu \mathrm{m}$ on symmetry axis). Furthermore, this symmetry axis, (AE) in Fig. 2, is subject to high velocities and temperature gradients. Let's note that the simulated temperatures are higher than the experimental ones and the simulated weld pool domain is slightly smaller than the one shown in the micrography, Fig. 4. This is probably due to the size of the thermocouple $(0.5 \mathrm{~mm})$ that are quite important with regards to the sample size $(4 \times$ $40 \mathrm{~mm}$ ) leading to measurement errors due to a non perfect thermal contact between sample surface and thermocouple tip.

In the following investigations, it is proposed to use an inverse approach to estimate two parameters of the heat flux: $\eta$ and $R_{B}$ as these two parameters were assumed from the literature. The parametric sensitivity analysis underlined the key role of these two parameters in the computational model [23]. The other parameters are more or less known with a good accuracy except measurement errors due to non perfect thermal contact for example.

\section{Inverse heat transfer problem (IHTP)}

Inverse heat transfer problem (ihtp) is generally formulated as: Find the unknown vector $\bar{p}=\left(\eta, R_{B}\right)$ such that the measured temperature $T_{\exp }(t)$ is equal to the calculated temperature $T_{\text {sim }}\left(x_{i}, t, \bar{p}\right)$ 


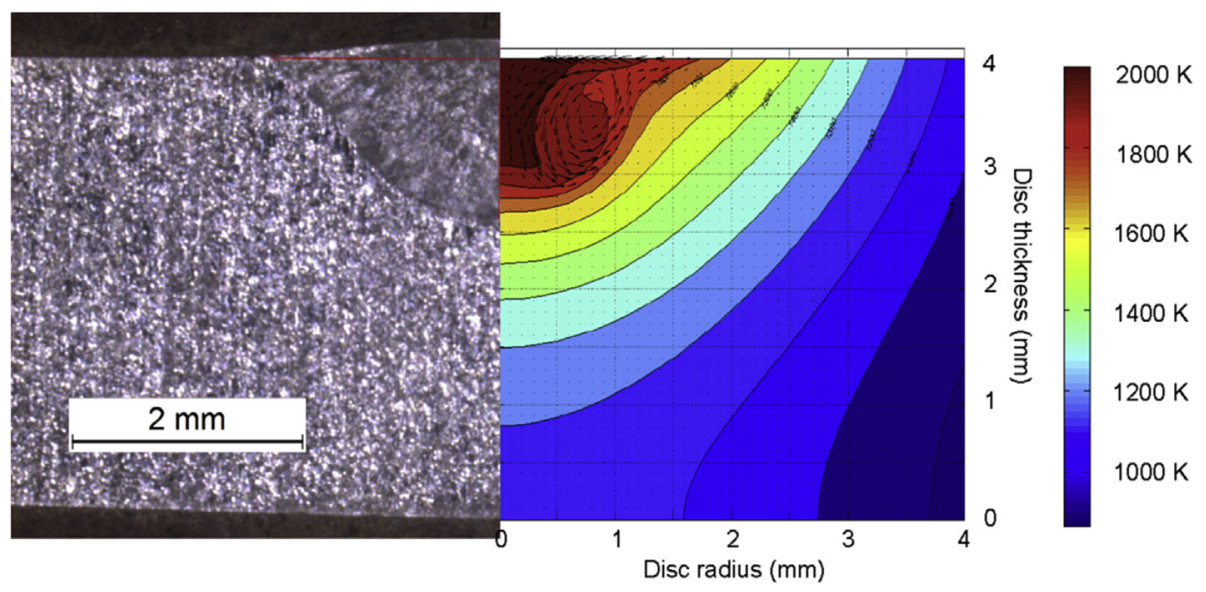

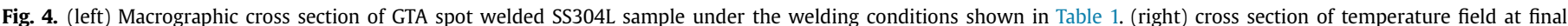
simulation time, $t=5.15 \mathrm{~s}$. Isotherm $1673 \mathrm{~K}$ corresponds to the liquid (mushy)/solid interface.

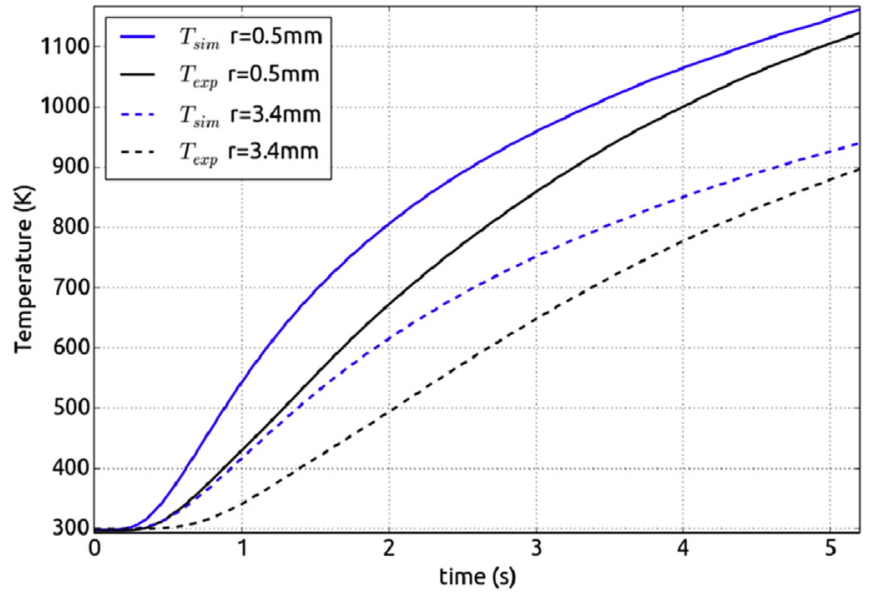

Fig. 5. The temperature evolutions of 2 points located on sample backside at $0.5 \mathrm{~mm}$ and $3.4 \mathrm{~mm} T_{\text {sim }}$ means simulated temperature while $T_{\exp }$ is for the measured temperature experimentally.

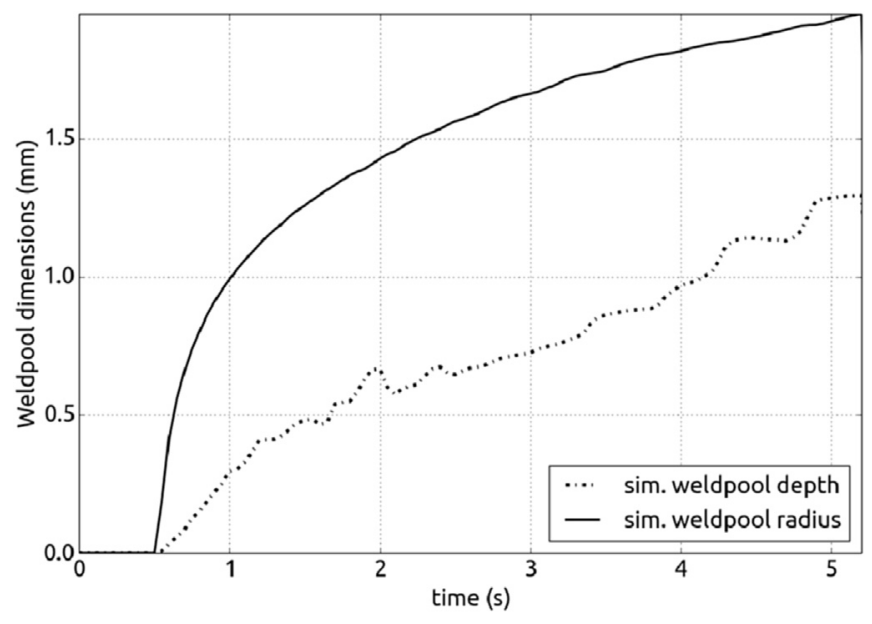

Fig. 6. Simulated weld pool width and depth (or penetration).

at each sensors located at point $x_{i}$ and for any time steps. This formulation is modified according to the least square sense and becomes [16]:
$S(\bar{p})=\frac{1}{2}\left[T_{\exp }-T_{\text {sim }}\right]^{T} W\left[T_{\exp }-T_{\text {sim }}\right]$

this later expression is also called objective function. Where, $\mathrm{W}$ is a diagonal weighting matrix and normally it is taken as the inverse of the covariance matrix of the measurement errors. As we don't know the standard deviation (error) on the input data (temperature), we set this to the unity matrix.

Now comes the second ihtp formulation: Find the unknown vector $\bar{p}=\left(\eta, R_{B}\right)$ which minimizes the objective function $S(\bar{p})$. Ihtp is known to be ill posed [16] as their solution can be non unique and unstable to a small change in the input data (experimental ones). A regularization technique can be used to stabilize the solution. Several regularization techniques can be used such as: LevenbergMarquardt [12,14], gold section [13] and conjugate gradient [15]. In the present work, the Levenberg-Marquardt (LM) technique is used as this approach is well suited when the number of parameter to estimate is low. Moreover, this technique is quite simple to program and generally robust. The LM technique implies a damping parameter that is large at the beginning and the technique is similar to the steepest descent method. Then this damping parameter decreases as the objective function decreases and the LM technique is similar to the Gauss Newton algorithm. This technique is well detailed in Ref. [16]. The LM technique was programmed in Matlab ${ }^{\circledR}$ as this software is connected to $\mathrm{Comsol}^{\circledR}$. Required values such as temperature, sensitivity of temperature field according to the unknown parameter are computed with $\mathrm{Comsol}^{\odot}$ then exported to Matlab $^{\circledR}$ in order to compute the new set of estimated parameters according the LM algorithm. The next section deals with numerical tests cases in order to demonstrate the feasibility to estimate the unknown parameters: $\eta$ and $R_{B}(t)$.

\subsection{Inverse analysis with numerical input data}

In the following investigations, three sets of numerical data (temperature and weld pool width evolutions) are used as ihtp input. These three sets have been computed with the following heat flux parameters: $\eta=0.68, R_{B 1}\left(t_{0}\right)=1.7 \mathrm{~mm}\left(\right.$ at $\left.t_{0}=0\right)$ and $R_{B 2}\left(t_{f}\right)=2.1 \mathrm{~mm}$. The Gaussian base radius evolve with time as follows:

$R_{B}(t)=\left(R_{B 2}-R_{B 1}\right) \frac{t}{t_{f}}+R_{B 1}$ 
The temperature was numerically measured respectively at $1 \mathrm{~mm}$ and $4 \mathrm{~mm}$ from centre back side. The first set of input data was merely the solution of this simulation (case 1). The two other sets of input data were defined as follows:

- Case 2: the input temperatures were initially measured at $0.8 \mathrm{~mm}$ and $4.2 \mathrm{~mm}$ on the back side while in the ihtp it was considered at $1 \mathrm{~mm}$ and $4 \mathrm{~mm}$.

- Case 3: the input were noised as follows:

$T_{\text {NOISE }}(t)=T_{\text {case } 1}(t)+\sigma(t) \times \phi(t)$

where $\sigma(t)=0.05 \times T_{\text {case } 1}(t)$ is the maximum standard deviation and $-1 \leq \phi(t) \leq 1$ a random function.

The ihtp runs three times and the results are discussed with regards to the set used as input. For each case, the initial guesses for the parameters were set to: $\eta=0.1, R_{B 1}=20 \mathrm{~mm}$ and $R_{B 2}=20 \mathrm{~mm}$. The results are reported in Figs. 7,8 and 9 for case 1 . All the investigated ihtp cases are summarized in Table 3. The results are discussed in section 3.3.

The ihtp was stopped when the objective function either reached a threshold value (1e-3) or the decrease between two iterations was inferior to $1 \%$. The final value of the objective function was used for computing the average standard deviation $\tilde{\sigma}$ with:

$S(\bar{p})^{f i n a l}=\frac{1}{2} n_{t} n_{S}\left(T_{\text {exp }}-T_{\text {sim }}^{\text {final }}\right)^{0.5}=\frac{1}{2} n_{t} n_{S} \tilde{\sigma}^{2}$

where, $n_{t}$ is the number of time step and $n_{S}$ is the number of sensors.

\subsection{Parameter estimation with experimental data}

The ihtp was solved according to the temperatures presented in Fig. 5, under the welding conditions given in Table 1 . The three unknown parameters $\left(\eta, R_{B 1}, R_{B 2}\right)$ were initialized respectively to $0.85,10 \mathrm{~mm}$ and $10 \mathrm{~mm}$ as it can be seen in Figs. 10 and 11 at the $1 \mathrm{st}$ iteration. The iterative procedure of the ihtp was stopped at the 6th iterations as the objective function reached the stopping criterion. Fig. 10 presents both the objective function evolution and estimation of efficiency as function of iteration number. The objective function decreased quickly until the 4th iteration and stabilized after. Fig. 11 reports the evolution of the two estimated radius with regards of iteration number. The value of the estimated parameters varied importantly until the 4th iteration before stabilizing around

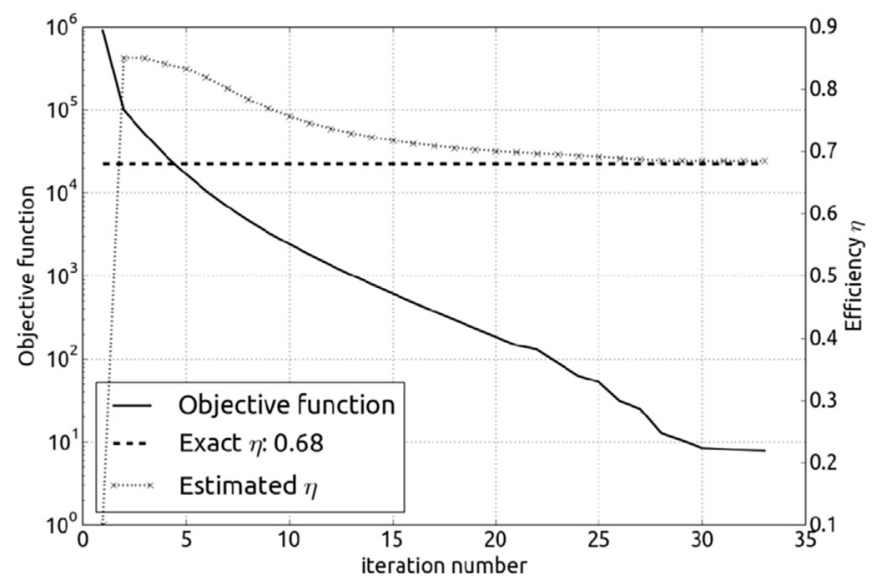

Fig. 7. Evolutions of objective function (left $Y$ axis) and estimated efficiency (right $Y$ axis) as a function of iteration number (numerical case: case 1 ).

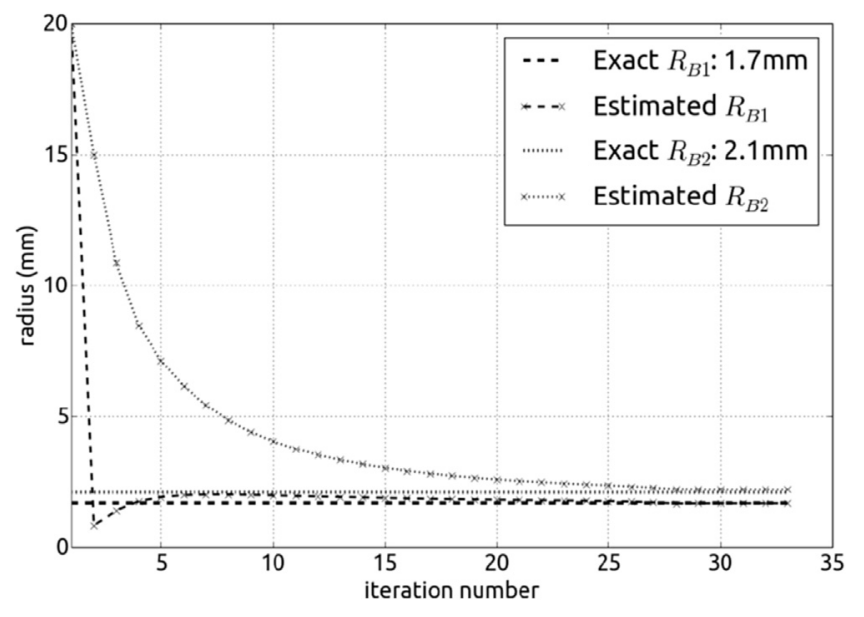

Fig. 8. Evolutions of the estimated gaussian radii as a function of iteration number (case 1). The exacts values are reported in the figure.

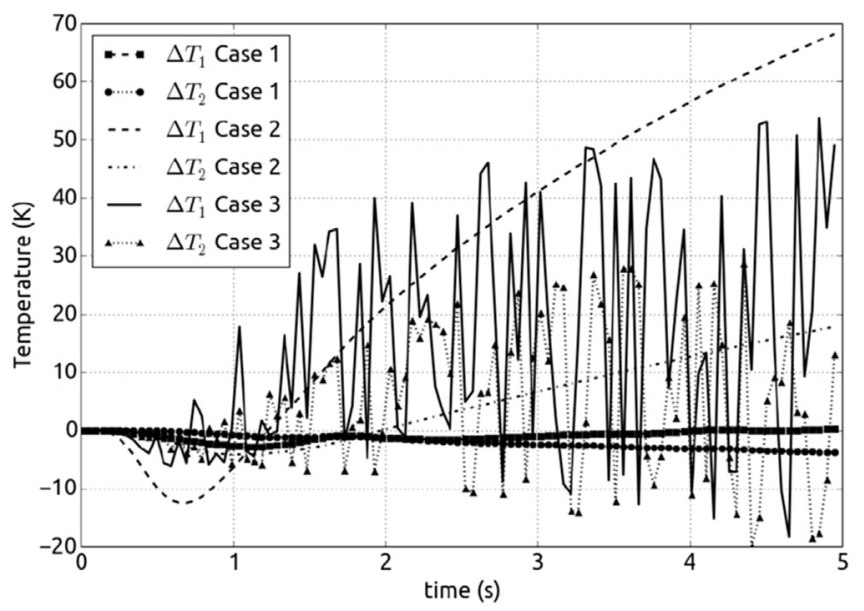

Fig. 9. Temperature residuals $\left(\Delta T(t)=T_{\text {input }}(t)-T_{\text {sim }}(t)\right)$ for each case and each sensor. The sensors were located on the sample backside at $r=1 \mathrm{~mm}$ and $4 \mathrm{~mm}$.

their final value. Final values are given in Table 4 (see Fig. 12)

Estimated values at the last iteration are $0.71,2.18 \mathrm{~mm}$ and $1.5 \mathrm{~mm}$ respectively for the efficiency, first and second Gaussian radii. Estimated value for $R_{B 1}$ Gaussian radius is surprisingly higher than the value $R_{B 2}$.

Fig. 12 presents the evolution of measured $T_{\exp }$ and calculated $T_{\text {sim }}$ temperatures at each sensors. The calculated temperatures match quite well the experimental ones especially between $t=1 \mathrm{~s}$ and $t=4 \mathrm{~s}$. This is confirmed with the computation of the average standard deviation, $\sigma \approx 18 \mathrm{~K}$, which has a low value. The temperature calculated at position $r=0.7 \mathrm{~mm}$ underestimates the observed temperature with the thermocouple below $1.3 \mathrm{~s}$. Temperature calculated at $r=3.8 \mathrm{~mm}$ fits almost perfectly with the measured one. A comparison between the experimental (from macrography study) and calculated weld pool shape is given in Table 5. The final dimensions are very similar with a slight lack of penetration for the simulated one.

\subsection{Discussion}

\subsubsection{Numerical investigation}

Case 1 (solved with ideal input data) converged monotonously towards the true values of the three parameters as expected. The 
Table 3

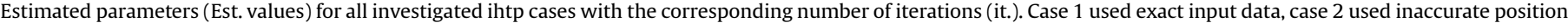
of sensors and case 3 considered random noise measurement added to input data of case 1 .

\begin{tabular}{|c|c|c|c|c|c|c|}
\hline \multicolumn{2}{|l|}{ Parameter } & \multirow{2}{*}{$\frac{\text { Efficiency } \eta}{0.68}$} & \multirow{2}{*}{$\frac{R_{B 1}(\mathrm{~mm})}{1.7}$} & \multirow{2}{*}{$\frac{R_{B 2}(\mathrm{~mm})}{2.1}$} & \multirow{2}{*}{$\frac{\text { Energy }\left(\mathrm{W} / \mathrm{m}^{2}\right)}{10097.9}$} & \multirow[t]{2}{*}{ Stand. dev. $\sigma(\mathrm{K})$} \\
\hline Exact value & & & & & & \\
\hline Case 1 (33 it.) & Est. value Error (\%) & $0.684 \leq 0.59$ & $1.679 \leq 1.24$ & $2.204 \leq 4.95$ & 9809.9 & 2.54 \\
\hline Case 2 (11 it.) & Est. value Error (\%) & $0.642 \leq 5.58$ & $1.343 \leq 21$ & $2.493 \leq 15.7$ & 10238.6 & 39.59 \\
\hline Case 3 (11 it.) & Esti. value Error (\%) & $0.695 \leq 2.2$ & $1.77 \leq 4.1$ & $2.34 \leq 11.4$ & 8906.6 & 27.53 \\
\hline
\end{tabular}

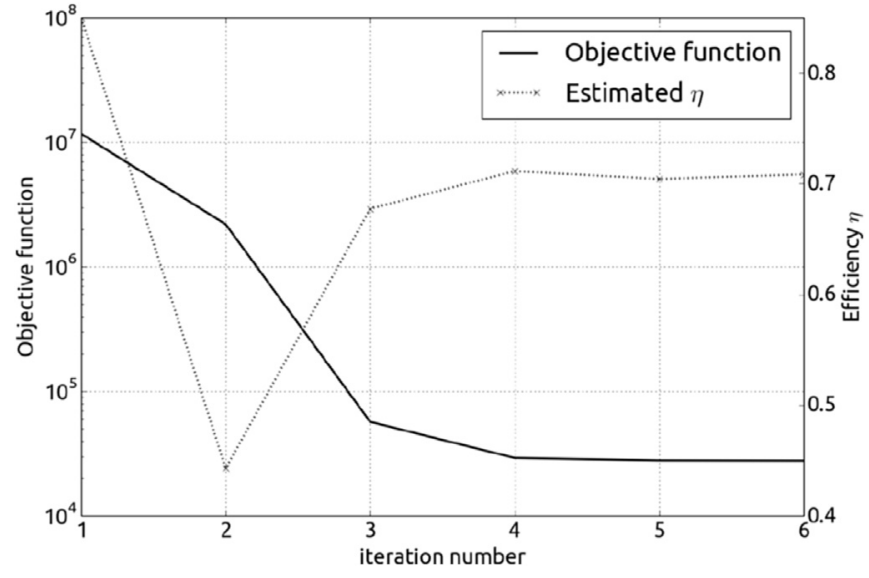

Fig. 10. Evolutions of the objective function and efficiency as function of iteration number (experimental data).

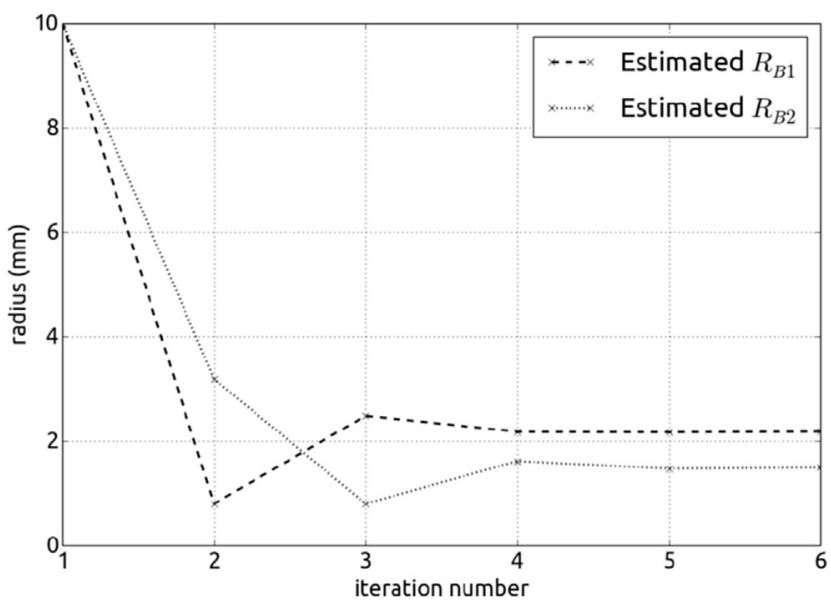

Fig. 11. Evolution of the two estimated radius with respect of iteration number (experimental data).

Table 4

Estimated heat source parameters at 6th iteration.

\begin{tabular}{lllll}
\hline Parameters & Efficiency $\eta$ & $R_{B 1}(\mathrm{~mm})$ & $R_{B 2}(\mathrm{~mm})$ & Standard deviation $(\mathrm{K})$ \\
\hline Estimated value & 0.708 & 2.18 & 1.49 & 17.7 \\
\hline
\end{tabular}

objective function reached the value of 7.8 at the stopping iteration which is low in comparison to its initial value: $9 \times 10^{5}$. This final value of the objective function led to an average standard deviation lower than $2.5 \mathrm{~K}$, see Table 3 . This residual is assumed to be due to numerical errors of the FE software. The efficiency and $R_{B 1}$ parameters are estimated with an excellent accuracy while the accuracy for $R_{B 2}$ is fair, under $5 \%$, see Table 3 .

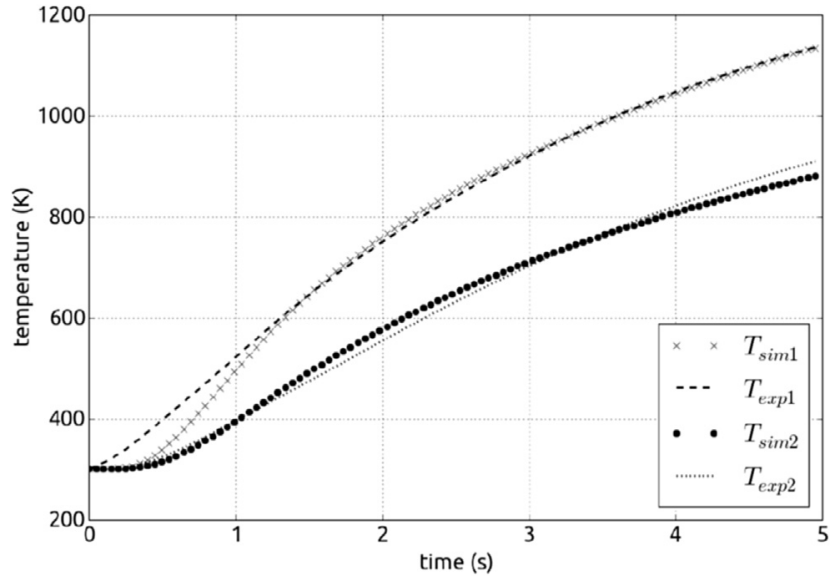

Fig. 12. Comparison between experimental and simulated temperatures. The positions of thermocouples were $0.7 \mathrm{~mm}$ and $3.8 \mathrm{~mm}$ from the backside centre, respectively for location 1 and 2 .

Table 5

Final weld pool dimensions (calculated at the final iteration) for high sulfur sample.

\begin{tabular}{lll}
\hline Weld pool & Experimental & Simulated \\
\hline Radius $(\mathrm{mm})$ & 2.0 & 2.05 \\
Depth $(\mathrm{mm})$ & 1.4 & 1.32 \\
\hline
\end{tabular}

Case 2 has considered errors on sensors position. The position of the sensors was modified by $\pm 0.2 \mathrm{~mm}$ (input temperatures were recorded at $0.8 \mathrm{~mm}$ and $4.2 \mathrm{~mm}$ while they were recorded at $1 \mathrm{~mm}$ and $4 \mathrm{~mm}$ in the ihtp). Temperature residuals show that the calculated temperatures are lower than the input ones, see Fig. 9. The sensor 1 exhibits a maximum difference of $70 \mathrm{~K}$ at final time. The estimated parameters are quite different of the expected values. The accuracy varies between $-5.6 \%$ for the efficiency to $-21 \%$ for $R_{B 1}$. The two gaussian radii were the most affected with the inaccuracy on the sensor position. However the integral of the heat flux, over the time and space, $\sim 10238 \mathrm{~W} / \mathrm{m}^{2}$, is quite similar to the true value of $10097 \mathrm{~W} / \mathrm{m}^{2}$, see Table 3. Despite these estimated parameters, the technique was able to estimate accurately the integral of the heat flux what is also important.

Case 3 has investigated the effect of noise measurement in the input data (temperatures and weld pool shape). This kind of error affected mostly $R_{B 2}$ as its value is overestimated by $11 \%$. As a consequence, the integral of the heat flux is then underestimated to 8906 , see Table 3. The large value of $R_{B 2}$ led to low values of energy (which is a function of $1 / R_{B 2}$ ). The Levenberg-Marquardt technique has filtered off the noise introduced on the input data. It can be observed in Fig. 9 through the temperature residuals as the calculated temperatures (ihtp solution) are smooth. Over the time interval, the temperature residuals vary between $-10 \mathrm{~K}$ and $50 \mathrm{~K}$, knowing that the average standard deviation is about $27.5 \mathrm{~K}$ see Fig. 9 and Table 3, that means the calculated temperatures also 
underestimate the input ones. This is due to the large value estimated for $R_{B 2}$ which leads to lower temperatures in the work-piece.

As conclusions of this numerical investigation, it was noticed that the ihtp is quite robust to noise measurement added to the input data but the ihtp is quite sensible to the accuracy on the position of the sensors. A small error on the sensor position about \pm $0.2 \mathrm{~mm}$ led to a poor estimation of Gaussian radius parameter. Furthermore, it is well known that thermocouple introduces a thermal contact resistance. This thermal contact resistance results in a delay of the thermocouple response as well as lower measured temperature. It is extremely important to know accurately the position of the thermocouple head and to improve its contact with the work-piece.

\subsubsection{Experimental investigation}

The analysis of the weld pool dimensions (at $t_{f}$ ) shows that the simulation fits quite well with the macrography of the weld spot. Furthermore, the experimental and calculated temperatures match very well for $t \geq 1.3 \mathrm{~s}$. Below $1.3 \mathrm{~s}$, the calculated temperature at $r=0.7 \mathrm{~mm}$ is strongly underestimated and the thermal dynamic behaviour is different. This is maybe due to an underestimation of efficiency or an overestimation of radius for $t \leq 1.3 \mathrm{~s}$. It has been noticed that the efficiency is generally better estimated than the Gaussian radius through the numerical investigated cases. Thus, the Gaussian radius is probably not properly estimated and lower than the estimated value. Unfortunately, a decrease of $R_{B 1}$ will result in more concentrated heating of the work piece and higher temperatures in its centre. To lower the heating, the final radius should be larger. The computation of the average Gaussian radius leads to $1.83 \mathrm{~mm}$ what seems closer to the expected value. The unexpected values of the Gaussian radii are probably due to thermocouple effects such as thermocouple size $(0.5 \mathrm{~mm})$ and the thermal contact resistance that generally lower the temperature during the transient state. The efficiency value is probably somewhat around 0.7 while the Gaussian radii are between $1.5 \mathrm{~mm}$ and $2.1 \mathrm{~mm}$. Another method would be to model the thermocouple tip in the simulation what requires a 3D modelling and not a $2 \mathrm{D}$ axisymmetry modelling. Such 3D simulation would limit the thermocouple effect but would increase drastically the computation time to hours maybe days against few minutes in the present case.

\section{Conclusion}

A multi-physics modelling of a static GTAW operation has been detailed which included heat transfer, fluid mechanics and electric potential in the aim to simulate the heating of the work-piece by the arc plasma and the weld pool growth. Both Marangoni (due to surface tension effects) and Lorentz (as welding current induces a magnetic force) forces were considered as they drive the molten metal flow. The simulation was solved with finite element software. Afterwards the stated multi-physics GTAW modelling has been used in an inverse iterative method in order to estimate parameters of the heat flux applied on the work-piece. The heat flux was modelled with a Gaussian function where process efficiency and its radial distribution required to be estimated as they are tightly dependent on welding process.

The Levenberg-Marquardt algorithm was implemented as regularization method of the inverse problem. The developed inverse problem was tested through few numerical cases. According to these tests, it has been pointed out that a small inaccuracy on the thermal sensors position led to mistaken heat flux parameters. Nonetheless, these mistaken estimated parameters gave a correct amount of the absorbed energy by the work-piece (integral of heat flux over time and space).

The inverse heat transfer problem was solved with temperatures measured during a static GTAW operation on SS304L with $39 \mathrm{ppm}$ of sulfur, a 70 A welding intensity, shielded with pure Argon and a $2.4 \mathrm{~mm}$ pure tungsten electrode. The estimated process efficiency was about 0.7 which is in good agreement with values found in the literature. The radial distribution was assumed to be time dependent in the heat flux model with two radii defined at $t_{0}$ and $t_{f}$. The estimated radius were respectively $2.1 \mathrm{~mm}$ and $1.5 \mathrm{~mm}$. It was expected close values for the two radii or a lower radius for $t_{0}$ than the one at $t_{f}$. It was noticed that the comparison of measured and calculated temperatures did not fit perfectly for $t<1.3 \mathrm{~s}$. This is probably due to some difficulties of the inverse method to estimated the parameters due to the low recorded temperatures at the beginning of operation added to thermocouple errors such as accuracy of its position and thermal contact error.

The ihtp appears to be a relevant approach for numerical investigation of welding problems. It gives a good approximation of the global energy delivered to the workpiece and a realistic weld pool size and shape evolutions. Further works could improve the ability to obtain predictive information by considering for example an evolution of efficiency with process cycle.

\section{References}

[1] Oreper GM, Eagar TW, Szekely J. Convection in arc weld pools. Weld Res Suppliment 1983:307s-12s.

[2] Kou S, Sun DK. Fluid flow and weld penetration in stationary arc welds. Metall Trans A 1985;16:203-13.

[3] Matsunawa A, Yokoya S, Asako Y. Convection in weld pool and its effect on penetration shape in stationary arc welds. In: Transactions of JWRI. Osaka 567 Japan: Welding Research Institute of Osaka University; 1987. p. 229-36.

[4] Natarajan R, Seppo A, Korpela A. Fluid dynamics of a stationary weld pool. Metall Trans A 1990;21:45-57.

[5] Fan HG, Tsai HL, Na SJ. Heat transfer and fluid flow in a partially or fully penetrated weld pool in gas tungsten arc welding. Int J Heat Mass Trans 2001;44:417-28.

[6] Tanaka M, Lowke JJ. Topical review: predictions of weld pool profile using plasma physics. J Phys D: Appl Phys 2007;40:1-23.

[7] Traidia A. Multiphysics modelling and numerical simulation of gta weld pools Ph.D. thesis. Ecole Polytechnique; 2011.

[8] Rosenthal D. The theory of moving source of heat and its application to metal transfer. Trans A.S.M.E. 1946;43:849.

[9] Pavelic V. Experimental and computed temperature histories in gas tungsten arc welding of thin plates. Weld J Res Suppl 1969;48:295s-305s.

[10] Goldak JA, Chakravarti AP, Bibby M. A new finite element model for welding heat sources. Metall Trans B 1984;15:299-305.

[11] Tsai NS, Eagar TW. Distribution of heat and current fluxes in gas tungsten arcs Metall Trans B 1985;16:841-6.

[12] De A, DebRoy T. Improving reliability of heat and fluid flow calculation during conduction mode laser spot welding by multivariable optimisation. Sci Technol Weld Join 2006;11(2):143-53.

[13] Goncalves CV, Vilarinho LO, Scotti GG. Estimation of heat source and thermal efficiency in gtaw process by using inverse techniques. J Mater Process Technol 2006;172:42-51.

14] Rouquette S, Guo J, Le Masson P. Estimation of the parameters of a gaussian heat source by the levenberg-marquardt method: application to the electron beam welding. Int J Therm Sci 2007;46:128-38.

[15] Dal M, Le Masson P, Carin M. Estimation of fusion front in 2d axisymmetric welding using inverse method. Int J Therm Sci 2012:55:60-8.

[16] Ozisik MN, Orlande HRB. Inverse heat transfer. 29 West 35th Street: Taylor \& Francis; 2000

[17] Traidia A, Roger F. Numerical and experimental study of arc and weld pool behaviour for pulsed current gta welding. Int J Heat Mass Transf 2011;54: 2163-79.

[18] Sahoo P, Debroy T, McNallan MJ. Surface tension of binary metal-Surface active solute systems under conditions relevant to welding metallurgy. Metall Trans B 1988;19:483-91.

[19] Rokhlin S, Guu A. A study of arc force, pool depression, and weld penetration during gas tungsten arc welding. Weld J 1993;72(8):381s-90s.

[20] Mills K. Recommended values of thermophysical properties for selected commercial alloys. Woodhead: Woodhead Publishing Series in Metals and Surface Engineering Series; 2002.

[21] Wu C, Zheng W, Wu L. Modelling the transient behaviour of pulsed current tungsten-inert-gas weldpools. Model Simul Mater Sci Eng 1999;7:15-23.

[22] Cho M. Numerical simulation of arc welding process and its application. Ph.D. thesis. The Ohio State University; 2006.

[23] Unnikrishnakurup S. Ph.D. thesis. Static gtaw: experimental and numerical investigations and heat flux parameters estimation, 2. Université Montpellier: 2014. 